\title{
THE INFLUENCE OF OBESITY ON HYDROXYCHLOROQUINE BLOOD LEVELS IN LUPUS NEPHRITIS PATIENTS
}

Tatiana Pedrosa ${ }^{1}$, Léonard de Vinci Kanda Kupa ${ }^{1}$, Sandra Gofinet Pasoto ${ }^{1}$, Nádia Emi Aikawa ${ }^{1}$, Eduardo Ferreira Borba ${ }^{1}$, Nilo JC Duarte ${ }^{3}$, Elaine Pires Leon ${ }^{1}$, Clovis Artur Silva ${ }^{1}$, Eloisa Bonfá1,*

1.Universidade de São Paulo, São Paulo (SP), Brazil.

*Corresponding author: eloisa.bonfa@hc.fm.usp.br

\section{BACKGROUND}

In 2016 the American Academy of Ophthalmology (2016-AAO) recommended a maximum daily hydroxychloroquine (HCQ) use of $5.0 \mathrm{mg} / \mathrm{kg}$ real body weight (RBW) taking into consideration minimizing eye toxicity. Retinopathy in systemic lupus erythematosus (SLE) patients was recently associated with obesity and this condition is progressively more common in these patients. However, the impact of obesity in HCQ blood levels remains controversial. The objective of this work was to determine if the 2016-AAO recommendation results in adequate and safe blood levels in obese lupus nephritis (LN) patients.

\section{MATERIALS AND METHODS}

A cross-sectional study was performed with $108 \mathrm{LN}$ patients under the prescribed 2016-AAO dose for at least 3 months. Lupus nephritis patients were assessed for demographic characteristics, body mass index (BMI), disease parameters, HCQ dose, concomitant treatment and HCQ blood levels measured by liquid chromatography-tandem mass spectrometry. Obesity was defined as $\mathrm{BMI} \geq 30 \mathrm{~kg} / \mathrm{m}^{2}$

\section{RESULTS}

Obesity was identified in 35/108 (32\%) LN patients. The calculation of HCQ daily dosage revealed that obese patients were under a lower prescribed daily dose according to the real body weight (RBW) [4.4 (2.9-5.4) vs. 4.9 (4.0-5.5) mg/kg/day, $\mathrm{p}<0.001$ ], but a very high daily dose according to the ideal body weight (IBW) [7.8 (6.1-9.4) vs. 5.9 (4.0-8.1) mg/kg/day, p<0.001]. The median of HCQ blood levels was significantly higher in obese compared to non-obese patients ( $1562 \pm 548.6 \mathrm{vs} .1208 \pm 448.9 \mathrm{ng} / \mathrm{mL}$, $p=0.002)$. Both parameters had a positive correlation with HCQ blood levels: $B M I(r s=0.263, p=0.006)$ and dose based on IBW ( $r S=0.248, p=0.0097)$. Multivariate linear regression analysis showed that only daily dose by IBW was associated with HCQ blood levels $(p=0.02)$.

\section{CONCLUSION}

Obese patients under the 2016-AAO prescribed dose of HCQ based on RBW have a very high HCQ blood levels compared to nonobese patients, with a potential increased risk of ocular toxicity. The use of 2016-AAO dose of HCQ according to the IBW for this group of patients should be considered.

Clinicaltrials.gov \#NCT0312243.

\section{FUNDING}

This work was supported by grants from Fundação de Amparo à Pesquisa do Estado de São Paulo (FAPESP) 2015/03756-4 to SGP, NEA, CAS and EB; 2017/03983-6 for the LC-MS/MS system, 2017/14352-7 to TNP and 2019/17272-0 to LVKK; and Conselho Nacional de Desenvolvimento Científico e Tecnológico (CNPq) (303422/2015-7 to CAS, \#306879/2018-2 to EFB and 305242/2019-9 to EB). 